\title{
Gastric resection and metabolic bone disease
}

\author{
C. N. Pulvertaft \\ County Hospital, York
}

IN RECENT years high frequencies of metabolic bone disease have been reported from Birmingham (Jones, Williams \& Nicholson, 1963), Adelaide (Deller, Edwards \& Addison, 1963; Deller \& Begley, 1963) and Aberdeen (Clark et al., 1964).

These reports have been interpreted by one of the observers, John Williams of Birmingham (Williams, 1966), as indicating that some abnormality of bone and/or calcium metabolism can be detected in about $20 \%$ of cases, five or more years after resection.

Dr Brian Morgan will discuss the problem of metabolic bone disease. I will try to relate these problems to partial gastrectomy of Polya type as seen in York, and will only discuss thinning of bone.

In 1964-65 we, the Gastric Clinic, in conjunction with Professor Paul Fourman's Clinical Investigation Unit, in particular Dr Morgan, surveyed our series of gastric operations (Morgan et al., 1965).

We came to the conclusion that partial gastrectomy does influence bone metabolism, but we differed from previous observers on the clinical significance of these changes, which we regard more as a fascinating physiological, rather than a major clinical, problem.

The York series is a complete cross-section of all cases, good and bad results, and all-age groups, whereas certainly in the Adelaide and Birmingham series, the patients were, at least to some extent, selected, as they represented a hospital population. This fact in itself may be sufficient to explain these differences of opinion.

\section{Method}

In estimating cortical bone change we concentrated on the second right metacarpal. The right hand was $\mathrm{X}$-rayed, under standard conditions, in a water bath containing an aluminium stepwedge (Morgan et al., 1967). The cortex could, therefore, be estimated by densitometry, Nordin's metacarpal index, or the simple measurement of the cortical thickness in millimetres. We preferred the last method (Morgan et al., 1967).

\section{Results}

We have demonstrated (Morgan et al., 1967) that the cortical thickness in normal subjects thins with increasing age, this being more marked in women than men, and that the metacarpal cortex in men with vagotomy and gastro-enterostomy or pyloroplasty does not differ from unoperated ulcer patients (Morgan, Pulvertaft, \& Fourman, 1966).

From the age of 40 onwards men with Polya resections have, on average, a slightly thinner cortex than the controls, and the difference increases with age, in particular after the age of 60. In women the difference is more marked and occurs at an earlier age, but by the age of 70 no difference can be detected, presumably because by then all women, as a group, are osteoporotic.

It is natural to suggest that these differences are related to the nutritional status of gastrectomy subjects, and most observers have suggested that it is the result of inadequate intake and/ or absorption, of calcium or vitamin $D$.

Nutritional status is, however, extremely difficult to define, and I have looked at this problem in many ways. I decided it was worth comparing the metacarpal cortex in male controls and Polya resections of similar weight and height. I, therefore, calculated the mean weight and standard deviation, for age, in the control group, and compared the mean cortex with Polya resections within the same definition. They were, in fact, very comparable. Polya resections with weights below 1 standard deviation had, however, distinctly thinner cortices throughout the age range. This observation did not hold for the control men.

We have studied the diets, using the 7-day Diary Method, of unoperated ulcer and postoperative patients. The mean daily intake for thirty-seven male ulcer patients and fifty-three post-gastrectomy subjects within this weight definition and aged 40-69 is shown in Table 1 ; the mean height for these two groups being identical. There is very little difference for the daily calorie, protein, calcium and vitamin $\mathbf{D}$ 
intake. For thirty-three post-gastrectomy patients below 1 standard deviation the daily consumption is appreciably smaller, but even here it should be adequate in all respects.

TABLE 1

Mean daily consumption (7-day Diary Method) for unoperated ulcer subjects (men) (1) within 1 standard deviation of the mean weight, for age, and men after Polya resection with weights within the same definition (2), and (3) below the limit of 1 standard deviation

\begin{tabular}{|c|c|c|c|c|c|c|}
\hline & & No. & Calorie & $\begin{array}{l}\text { Protein } \\
\text { (g) }\end{array}$ & $\underset{(\mathrm{mg})}{\text { Calcium }}$ & $\begin{array}{l}\text { Vitamin } \\
\text { D (i.u.) }\end{array}$ \\
\hline \multicolumn{2}{|c|}{ Ulcer controls (1) } & 37 & 3132 & 95 & 1341 & 205 \\
\hline $\begin{array}{l}\text { Polya } \\
\text { resections }\end{array}$ & $\begin{array}{l}\text { (2) } \\
\text { (3) }\end{array}$ & $\begin{array}{l}53 \\
33\end{array}$ & $\begin{array}{l}3060 \\
2624\end{array}$ & $\begin{array}{l}90 \\
80\end{array}$ & $\begin{array}{r}1094 \\
935\end{array}$ & $\begin{array}{l}171 \\
117\end{array}$ \\
\hline
\end{tabular}

The group of patients with low weights, however, represent a mixed group, that is to say, subjects who would, with or without operation, have had this low body weight, and those, probably some $60 \%$ of the number, who have lost weight as a result of the operation.

I am indebted for the next clue to the work of Dr John Lever of Leeds. He estimated the total body fat (TBF) in a series of our patients by skin fold measurements. When the TBF was expressed as a percentage of the total body weight (TBW) we found a mean cortex of $4.1 \mathrm{~mm}$ for sixty-nine men with less than $10 \%$ TBF, compared to $4.7 \mathrm{~mm}$ for thirty-nine men with more than $15 \% \mathrm{TBF}$, a difference that is statistically significant $(P<0.01)$. The mean age for these groups were identical, 61.8 and 61.1 years, respectively.

This, however, was only a sample of our series, and I, therefore, applied Hume's equation (Hume, 1966) for estimating lean body mass, and again expressed the TBF as a percentage of the total body weight. This formula gives different estimates of TBF to the skin fold method and the findings were not directly comparable.

However, it is clear (Fig. 1) that the percentage of TBF of TBW differs in the gastrectomy men to the control men (ulcer patients with either no operation or with a vagotomy and gastroenterostomy or pyloroplasty).

In Table 2 the frequency of thin cortex (here arbitrarily defined as $<4.00 \mathrm{~mm}$ ) is shown for subjects, Polya resections and controls, with less than $22 \% \mathrm{TBF}$ and more than $27 \%$ TBF. For men with at least $27 \%$ TBF the frequency $(8.3 \%)$ is the same for Polya resections and controls ; for those with $22 \% \mathrm{TBF}$, or less, the frequency is $22.4 \%$ for Polya resections and
$15.1 \%$ for controls. The difference between the Polya groups is significant $(P<0.001)$. While there is a higher frequency for controls with less than $22 \%$ TBF than those with more than $27 \%$ TBF the difference is not significant $(P>0.20)$; the difference between controls and Polyas with a low percentage of TBF is also not significant. It is only in men with $22 \%$ or less TBF that any difference between operated and unoperated men can be detected. It is because a higher proportion $(46 \%)$ of Polya resections fall into this group than the controls $(24.5 \%)$ that Polya resections, as a whole, appear to have a high frequency of thin cortex.

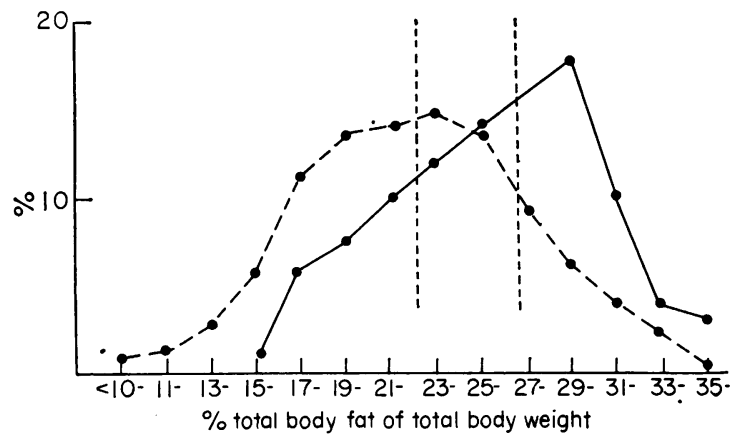

FIG. 1. Distribution of percentage total body fat of total body weight for men aged 40-49. Controls, 269 ( $-O$ and Polya, 611 (O- - $)$ resections.

TABLE 2

Frequency of thin cortex $(<4.00 \mathrm{~mm})$ for controls and Polya resections (men) with up to $22 \%$ and more than $27 \%$ total body fat

\begin{tabular}{lcclll}
\hline & \multicolumn{2}{c}{$<22 \%$} & & \multicolumn{2}{c}{$>27 \%$} \\
\cline { 2 - 3 } \cline { 5 - 6 } & No. & Thin cortex & & No. & Thin cortex \\
\hline Controls (1) & 66 & 10 & & (3) 133 & 11 \\
Polyas (2) & 304 & 68 & & (4) 134 & 11 \\
\hline
\end{tabular}

Significance: (1) and(2) $P>0.20$; (1) and (3) $P>0.20$; (2) and (4) $P<0.001$.

The mean cortex in relation to age, $40-69$, for controls and Polya resections with $27 \%$ or more TBF, and Polya resections with less than $22 \%$ TBF is shown in Fig. 2.

Up to the age of 60 the mean cortex for controls and Polyas with a high percentage of TBF is the same, but after this age the cortex thins for men with resection. Men with a low percentage TBF following resection have a thinner mean cortex at all ages up to 70 than those with high TBF, but the difference is small be- 
tween the ages of 60 and 70, and does not exist after the age of 70 (not shown in Fig. 2).

These findings suggest that there are two factors leading to thinning of the cortex after resection, that is to say nutrition and age. Whether the nutritional factor is due to decreased intake of food or to malabsorption is still debateable.

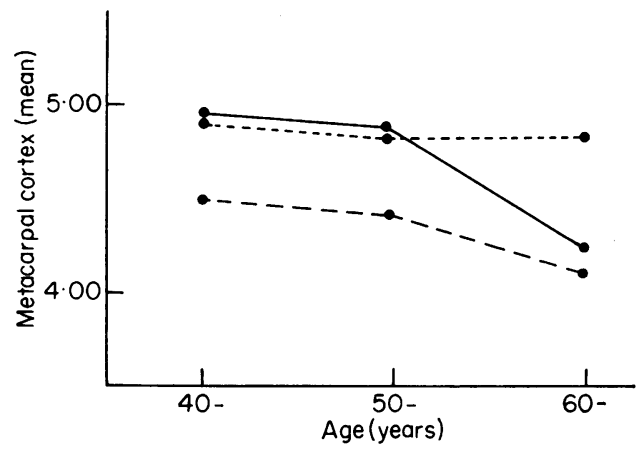

Fig. 2. Mean metacarpal cortex, for men, controls and Polya resections, aged $40-69$, in relation to percentage of total body fat of total body weight.

, 4.68 , controls, total body fat $27 \%$ and over. , 4.43 , Polya, total body fat $27 \%$ and over. , Polya, total body fat under $22 \%$.

Earlier I expressed the opinion that this was more a physiological than a clinical problem. It is, however, extremely difficult to determine, with accuracy, the morbidity resulting from the loss of bone, that is to say an increase in the frequency of severe osteoporosis or risk of fracture in the elderly.

We found that backache was no more common after operation than without operation, but backache is an unreliable guide to the state of the bones. A few patients, of similar order to the figures given by Dr Morgan for osteomalacia, had very thin bones with spinal deformity, but these were mainly elderly women, in whom these changes happen even without operation.

Dr J. D. Currey, of the University of York, has studied our data, and, in his opinion, the loss of bone which follows resection will have a minimal influence in increasing the risk of fracture, even in the elderly.

We recognize that the clinical problem does exist, but the number of patients affected is small.

\section{References}

Clark, C.G., Crooks, J., Dawson, A.A. \& Mitchell, P.E.G. (1964) Disordered calcium metabolism after polya partial gastrectomy. Lancet, i, 734.

Deller, D.J., Edwards, R.G. \& Addison, M. (1963) Metabolic effects of partial gastrectomy with special reference to calcium and folic acid. I. Changes in calcium metabolism and the bones. Gut, 5, 218.

Deller, D.J. \& Begley, M.D. (1963) Calcium metabolism and the bones after partial gastrectomy. I. Clinical features and radiology of the bones. Aust. Ann. Med. 12, 282.

Hume, R. (1966) Prediction of lean body mass from height and weight. J. clin. Path. 19, 289.

Jones, C.T., Williams, J.A. \& Nicholson, G. (1963) Partial Gastrectomy (Ed. by F.A.R. Stammers and J.A. Williams), p. 190. Butterworths, London.

Morgan, D.B., Paterson, C.R., Pulvertaft, C.N., Woods, C.G. \& Fourman, P. (1965) Search for osteomalacia in 1228 patients after gastrectomy and other operations on the stomach. Lancet, ii, 1085.

Morgan, D.B., Pulvertaft, C.N. \& Fourman, P. (1966) Effects of age on the loss of bone after gastric surgery. Lancet, ii, 772.

Morgan, D.B., Spiers, F.W., Pulvertaft, C.N. \& Fourman, P. (1967) The amount of bone in the metacarpal and the phalanx according to age and sex. Clin. Radiol.1, 101.

Williams, J.A. (1966) Post-gastrectomy bone disease in Postgraduate Gastro-enterology (Ed. by T.J. Thomson \& I. E. Gillespie), p. 290. Bailliere, Tindall \& Cassell, London. 